\title{
Campylobacter Concisus and Its Effect on the Expression of CDX1 and COX2
}

\author{
Behrooz Mozaffari Namin ${ }^{1,2}$, Mohammad Mehdi Soltan Dallal ${ }^{3,4 *}$
}

\begin{abstract}
Background: Barrett's oesophagus (BO) is a pre-malignant condition in which normal squamous epithelium of the lower oesophagus and gastresophageal junction is replaced by columnar cells and progress to oesophageal adenocarcinoma. The increase burden of oesophagus cancer morbidity and mortality worldwide make study of factors involved in the pathogenesis of BO essential. However, most of studies that examine the environmental risk factors associated with increased incidence and prevalence of $\mathrm{BO}$ have largely ignored the potential role of bacteria in disease aetiology. Aims: This study examined the role of Campylobacter concisus isolated from Barrett's and adenocarcinoma patient samples as one of possible environmental factors in the progression of Barrett's oesophagus to oesophagus adenocarcinoma. Methods: We focused on the effect of $C$. concisus on the expression caudal type homeobox 1 gene (CDX1) and cyclooxygenase-2 (COX-2) in three BO cell lines using quantitative real-time PCR. In addition, the attachment and invasion characteristics of $C$. concisus were also tested. Results: Results showed that $C$. concisus had a strong attachment to the cell lines and induce the expression of CDX1 in Barrett's cell lines in a time-dependent manner. Conclusion: Findings indicate that $C$. concisus could be as a new challenge in the progression of BO to adenocarcinoma.
\end{abstract}

Keywords: Campylobacter concisus- Barrett's oesophagus- COX2- CDX1

Asian Pac J Cancer Prev, 19 (11), 3211-3216

\section{Introduction}

Barrett's oesophagus (BO) is a condition in which stratified squamous epithelium lining the oesophagus is replaced by columnar shape epithelium and can develop into the oesophageal adenocarcinoma (OA). Although gastro-oesophageal reflux disease (GORD) is the main cause of $\mathrm{BO}$, the mechanisms involved in the progression of $\mathrm{BO}$ to $\mathrm{OA}$ are unclear. The prevalence of $\mathrm{BO}$ is about $10-14 \%$ of individuals with GORD and in $\mathrm{OA}$ is $0.2 \%$ to $2.1 \%$ (Jonge et al., 2014). In the past three decades, data show that the prevalence of OA has increased in the UK and the Western Hemisphere (Gibson et al., 2013). It has been demonstrated that the progression of BO to OA involved multi-step alterations of gene expression, epigenetic, and/or microenvironmental factors (Leung et al., 2014).

\section{Objective}

Metaplastic changes of $\mathrm{BO}$ epithelium create a new microenvironment, which is colonized by a variety of bacterial species. These organisms compete with each other and try to evade/manipulate host immune system in order to circumscribe host responses. Bacteria metabolite and toxin induce chronic inflammation, which drives or exacerbate neoplastic changes. Evidence shows that more than $15 \%$ of carcinogenesis can be attributed to the bacterial infection for instance Helicobacter pylori role in gastric cancer and mucosal-associated lymphoid tissue lymphoma, Streptococcus bovis in colon cancer, and Chlamydia pneumonia in lung cancer. This is possible by host cell invasion, alternation of cell cycle, DNA damage, subversion of cell division and apoptosis, and releasing different cytokines (Leung et al., 2014).

Studies on mucosal biopsies of $\mathrm{BO}$ and OA patients have demonstrated that bacterial community shift from Gram positive to Gram negative bacteria including the predominance of Campylobacter population with a high preponderance of C. concisus (Rosenvinge et al., 2013). C. concisus pathogenicity has been studied in periodontal disease, children's diarrhoea and inflammatory bowel disease (Macfarlane et al., 2009; Kaakoush et al., 2011). The pathogenic potential of $C$. concisus and its association with intestinal diseases make them a good candidate for potential pathogen in BO. This association might involve one of those mechanisms presented by Yang (2012) such as modulating CDX1 and COX2 signalling pathway through bacterial lipopolysaccharide. Consequently, 
evaluating effect of $C$. concisus on the expression of COX2, and CDX1 might highlight new aspect of microbial involvement in $\mathrm{BO}$ progression. This study aimed to explore the effect of C. concisus in the modulation of these biomarkers on a cell culture model with three oesophageal cell lines.

\section{Materials and Methods}

\section{Bacterial strains}

The $C$. concisus strain used in this study were isolated from mucosal biopsies of OA patients and healthy volunteers as described by Mozaffari namin (2015a). Briefly, C. concisus was grown and sub-cultured every three days on Wilkins-Chalgren (WC) agar (Oxoid, Basingstoke, Hamps, UK), and incubated at $37^{\circ} \mathrm{C}$ under an atmosphere of $10 \% \mathrm{H}_{2}, 10 \% \mathrm{CO}_{2}$ and $80 \% \mathrm{~N}_{2}$, in an anaerobic cabinet (Don Whitley, Shipley, UK).

\section{Epithelial cell culture and co-culture assays}

Three cell lines were used in this study; the Barrett's-associated adenocarcinoma cell line FLO-1, CP-A (non-dysplastic metaplasia), and CP-D (high-grade dysplastic metaplasia), described previously Mozaffari Namin et al., (2015a). In brief, FLO-1 cells were grown in Dulbecco's Modified Eagle Medium (DMEM) (Sigma-Aldrich, UK), and CP-A and CP-D cell lines were maintained in keratinocyte serum-free medium (KSFM, Invitrogen, UK). For co-culture assays, cells were then seeded at $5 \times 10^{5}$ cells $\mathrm{ml}^{-1}$ into 6-well micro plates (Corning, UK), in $3 \mathrm{ml}$ of complete medium. Cells were allowed to form semi-confluent monolayers for adherence and invasion assays.

\section{In vitro adhesion assays}

To determine the pathogen's adhesive abilities, FLO-1 cells were grown on $15 \times 15 \mathrm{~mm}$ sterile glass coverslips in 6-well tissue culture plates, and incubated as described previously. Coverslips were then washed three times with PBS and incubated in new antibiotic-free media containing $3 \times 10^{7} \mathrm{ml}^{-1}$ of C. concisus. Plates were incubated at $37^{\circ} \mathrm{C}$ for $15 \mathrm{~min}, 1$ and 3 hours. At each time point, coverslips were washed gently three times by dipping in warm PBS to remove non-adherent bacteria. Adherent bacteria were stained by two different methods; safranin and propidium iodide. In safranin staining, the cells were fixed in $95 \%$ methanol for $5 \mathrm{~min}$, dried, and performed Gram stain only with safranin, and live/dead staining with propidium iodide $\left(1.5 \mu \mathrm{lml}^{-1}\right)$ as described previously by Macfarlane et al., (2004). Each assay was performed in duplicate and repeated three times. Number of adherent bacteria was counted in 20 randomly selected microscopic areas then viewed and counted by fluorescent microscopy.

\section{In vitro invasion assays}

Approximately $3 \times 10^{7} \mathrm{ml}^{-1}$ bacteria were added to confluent FLO-1 cell monolayers in 6-well micro plates and incubated as descried above, for $0,1,3,5,7$ hours. Subsequently, extracellular bacteria were killed by addition of $200 \mu \mathrm{g} \mathrm{ml}^{-1}$ gentamicin as a routine lab method to eradicate extracellular bacteria and its concentration was useful for incubation time. Cells were washed three times with PBS, and intracellular bacteria were enumerated after lysis of the cells using $1 \%$ Triton $\mathrm{X}-100$ in PBS, and plate counting.

\section{$m R N A$ isolation and real-time quantitative PCR}

Expression profiles for selected biomarker genes by FLO-1 and BO cell lines after stimulation by C. concisus were determined relative to the GAPDH housekeeping gene by extraction of mRNA, cDNA synthesis, and quantification by real-time PCR (qPCR), as described below.

FLO-1, CP-A and CP-D cells challenged with C. concisus were harvested and total RNAs were isolated using RNA easy kit (Qiagen, UK), including $15 \mathrm{~min}$ on-column DNase step and reverse transcribed using the Quick reverse transcription system (Promega) with specific primer pairs (Table 1) as per the manufacturer's instructions. Synthesised cDNAs were aliquoted $(2 \mu 1)$ and stored at $-80^{\circ} \mathrm{C}$ prior analysis as described by Bahrami et al., (2014). Briefly qPCR was carried out done using an iCycler detection system and iQ SYBR Green Supermix. Test samples were added in triplicate at $2 \mu 1$ per well in a $20 \mu \mathrm{l}$ total reaction volume with appropriate annealing temperature (Table 1). Target gene copy numbers were then extrapolated from appropriate standard curves and normalised against the house keeping gene (GAPDH) using $\triangle \mathrm{CT}$ method. Results are expressed as averages of three separate experiments.

\section{Statistical analysis}

Data are reported as means \pm standard errors of mean (SEM). Repeated-measurement two-way ANOVA analysis followed by Bonferroni post-hoc test was used for statistical analysis between different groups. P values of $<0.05$ was considered as statistically significant. Data analysis was undertaken using the GraphPad Prism, version 4 (GraphPad Software Inc, San Diego, CA).

\section{Results}

\section{Bacterial adhesion}

Bacterial adhesion assay of BO cells was investigated as a prerequisite for cell invasion. This was assessed at different time points by confocal microscopy through the live/dead staining and safranin staining. Adhesion observations displayed that $C$. concisus aggregated and formed microcolonies to increase its adhesion abilities, but it was unable to invade the BO cell lines (Figure 1).

\section{Effects of C. concisus on cellular biomarker expression}

Molecular analyses showed that significant difference was observed on the expression of CDX1 after 3-hour in FLO-1 cell line $(p<0.001)$ (Table 2), while it was not detectable in both CP-A and CP-D cell lines (Table 3, 4). Results of co-culture in the COX2 expression showed that it has not been detected in FLO-1 cell line $(\mathrm{p}<0.001)$ (Table 2) and its expression was no more than control in both cell lines, CP-A and CP-D $(\mathrm{p}<0.001)$ (Table 3, 4). 
DOI:10.31557/APJCP.2018.19.11.3211

Campylobacter Concisus and oesophageal Cancer

Table 1. Primer Sequences Used in the Real-time Quantitative PCR and Their Characteristics

\begin{tabular}{|c|c|c|c|c|c|}
\hline \multicolumn{2}{|l|}{ Primer set } & Primer sequence $(5 \phi-3 \phi)$ & $\mathrm{TM}\left({ }^{\circ} \mathrm{C}\right)$ & $\begin{array}{l}\text { Product } \\
\text { size (bp) }\end{array}$ & Reference \\
\hline \multicolumn{2}{|c|}{ Campylobacter concisus } & $\begin{array}{l}\text { F: CAGTATCGGCAATTCGCT } \\
\text { R: GACAGTATCAAGGATTTACG }\end{array}$ & 60 & 306 & (Enberg J and Bang, 2005) \\
\hline GAPDH & $\begin{array}{l}\text { Glyceraldehyde-3-phosphate } \\
\text { dehydrogenase }\end{array}$ & $\begin{array}{l}\text { F:GGAAGGTGAAGGTCGGAGTC } \\
\text { R:TCAGCCTTGACGGTGCCATG }\end{array}$ & 56 & -13 & (Furrie et al., 2007) \\
\hline $\mathrm{COX} 2$ & Cyclooxygenase-2 & $\begin{array}{l}\text { F:GTGTTGCGGAGAAAGGAGTCAT } \\
\text { R:ACTTTCAGCATTTTGGCATCTTG }\end{array}$ & 64 & -14 & (Maaser et al., 2008) \\
\hline CDX1 & Caudal related homeobox 1 & $\begin{array}{l}\text { F:AGCGCAAAGTGAACAAGAAGAAACAG } \\
\text { R:GGGGCTATGGCAGAAACTCCTCT }\end{array}$ & 60 & -15 & (Mizoshita et al., 2013) \\
\hline
\end{tabular}

TM, annealing temperature; bp, base pairs

Table 2. Fold Change mRNA Expression for Biomarkers in FLO-1 Cell after Co-culture with C. concisus

\begin{tabular}{lcccc}
\hline \multicolumn{2}{c}{ CDX1 } & \multicolumn{2}{c}{ COX2 } \\
\hline Time & $\mathrm{T}$ & $\mathrm{C}$ & $\mathrm{T}$ & $\mathrm{C}$ \\
1h & $932 \pm 1.65$ & $7181 \pm \mathrm{ND}$ & $\mathrm{ND}$ & $41341 \pm 3$ \\
3h & $10122 \pm 2.65$ & $8365 \pm \mathrm{ND}$ & $\mathrm{ND}$ & $38238 \pm 2.16$ \\
$5 \mathrm{~h}$ & $970 \pm 1.45$ & $7033 \pm \mathrm{ND}$ & $\mathrm{ND}$ & $44667 \pm 3.45$ \\
$7 \mathrm{~h}$ & $861 \pm 1.72$ & $8511 \pm \mathrm{ND}$ & $\mathrm{ND}$ & $35342 \pm 3.2$ \\
P value & \multicolumn{2}{c}{$* *$} & & $* *$ \\
\hline
\end{tabular}

FLO-1 cells were stimulated with C. concisus for 1-7 h, samples mRNA was isolated, cDNA were prepared and real-time PCR analysis was carried out using specific primers for CDX1, COX2 and GAPD. Data are presented as mean \pm SEM of triplicate experiments. Quantitative PCR analysis of stimulated cells compared with non-stimulated controls, analysed by two-way ANOVA followed by Bonferroni post-hoc test analysis. T, test; C, control (cell without bacteria); ND, not detected. **, $\mathrm{P}<0.001$ significantly different from control values.

\section{Discussion}

\section{Discussion and Conclusion}

Most of researches on the etiology of $\mathrm{BO}$ have focused on various risk factors taking into account both environmental and genetic factors (Lim and Fitzgerald, 2013). However, these studies did not adequately address the role of environmental factor such as bacteria. We propose bacteria as a key risk factor for $\mathrm{BO}$, focusing on the role of $C$. concisus. Our results showed that $C$. concisus could modulate expression of

Table 3. mRNA-fold Differences Expression for Biomarkers in CP-A Cell Lines after Co-culture with C. concisus

\begin{tabular}{lcccc}
\hline & \multicolumn{2}{c}{ CDX1 } & \multicolumn{2}{c}{ COX2 } \\
\hline Time & T & C & T & C \\
1h & ND & $1327 \pm 1.6$ & $19 \pm 1.2$ & $184 \pm 1.3$ \\
$3 \mathrm{~h}$ & ND & $1575 \pm 2$ & $35 \pm 1$ & $170 \pm 1.16$ \\
$5 \mathrm{~h}$ & ND & $1619 \pm 1.85$ & $65 \pm 1.1$ & $220 \pm 1.45$ \\
$7 \mathrm{~h}$ & ND & $1420 \pm 1.35$ & $100 \pm 2$ & $231 \pm 1.23$ \\
P value & \multicolumn{2}{c}{$* *$} & \multicolumn{2}{c}{$* *$} \\
\hline
\end{tabular}

CP-A cells were challenged with organism and then after extracting mRNA and preparing cDNA qPCR was conducted. Results are shown as means \pm SEM from three independent experiments compared with non-stimulated controls, analysed by two-way ANOVA followed by Bonferroni post-hoc test analysis. T, test; C, control (cell without bacteria); ND, not detected. ${ }^{* *}, \mathrm{P}<0.001$ significantly different from control values.
Table 4. mRNA-fold Differences Expression for Biomarkers in CP-D Cell Lines after Co-culture with C. concisus

\begin{tabular}{lcccc}
\hline & \multicolumn{2}{c}{ CDX1 } & \multicolumn{2}{c}{ COX2 } \\
\hline Time & T & $\mathrm{C}$ & $\mathrm{T}$ & $\mathrm{C}$ \\
$1 \mathrm{~h}$ & $\mathrm{ND}$ & $9747 \pm 2.6$ & $43 \pm 1.89$ & $4716 \pm 1.3$ \\
$3 \mathrm{~h}$ & $\mathrm{ND}$ & $12000 \pm 3.1$ & $79 \pm 1.2$ & $6000 \pm 1.16$ \\
$5 \mathrm{~h}$ & $\mathrm{ND}$ & $12000 \pm 3.1$ & $227 \pm 1.54$ & $6930 \pm 1.45$ \\
$7 \mathrm{~h}$ & $\mathrm{ND}$ & $10055 \pm 3.81$ & $400 \pm 2.3$ & $6324 \pm 1.23$ \\
P value & \multicolumn{2}{c}{$* *$} & \multicolumn{2}{c}{$* *$}
\end{tabular}

CP-D cells were challenged with organism and then after extracting mRNA and preparing cDNA qPCR was conducted. Results are shown as means \pm SEM from three independent experiments compared with non-stimulated controls, analysed by two-way ANOVA followed by Bonferroni post-hoc test analysis. T, test; C, control (cell without bacteria); ND, not detected. ${ }^{* *}, \mathrm{P}<0.001$ significantly different from control values.

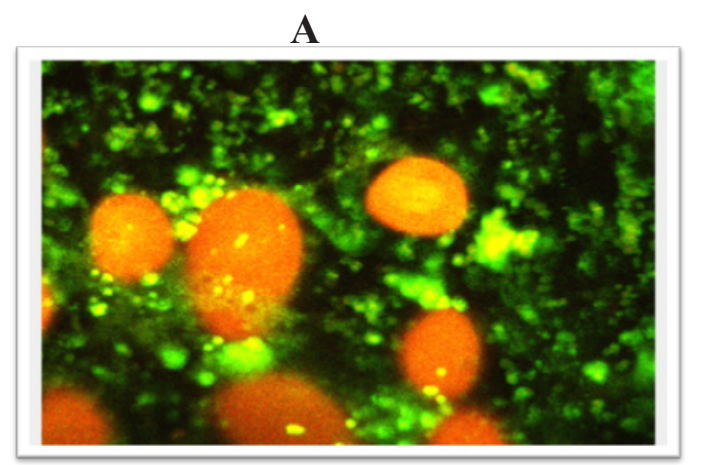

B

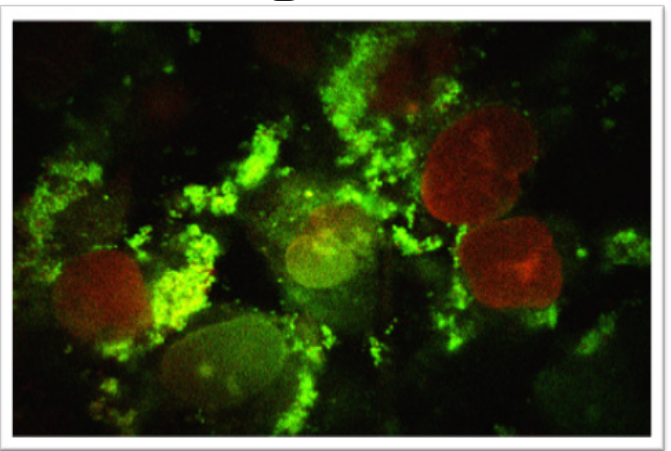

Figure 1. Fluorescence Microscopy Images of CP-D Cell Line co-cultured with $C$. concisus. (A) Live and dead staining with propidium iodide after 15 minute coculture which shows bacteria are motile around the cells. Cells are shown in red colour and microbes are in yellow and green. (B) Staining with propidium iodide after 90 min, arrow shows bacteria have started to aggregate and surround the cells. Original magnification, $\times 100$. 
CDX1 in FLO-1. Current studies have shown organism could induce Toll-like receptors (TLRs) and expression of COX2 in HT-29 cell line (Ismail et al., 2013). Data presented by Blackett et al., (2013) revealed initiation expression of different cytokines (TNF $\alpha$, IL18), and p53 (Mozaffari namin et al., 2015b) and also their expression in a primary study on $\mathrm{BO}$ and OA patient samples were all the effect of C. concisus. In addition, different studies have shown increased expression of CDX1 in BO has induced cell differentiation (Tamagawa et al., 2012) and alternation in the $\mathrm{p} 53$ expression resulting in increasing BO transition (Gajjar et al., 2012). These increase possibility of bacterial impacts on the expression of biomarkers involved in the progression of BO to OA or Barrett's pathogenesis.

Campylobacters express various virulence factors that enable them to adhere and invade host defence mechanisms. Different potent cytotoxic proteins and enzymes, such as haemolysin and cytolethal distending toxin (CDT) facilitate campylobacter virulence (Kaakoush et al., 2010). Campylobacter concisus ATCC13826 synthesizes two types of toxins, ZOT (zonula occludens toxin) and CDT, secretes 86 proteins, and has 25 genes associated with virulence or colonization activities (Kalischuk et al., 2011; Kaakoush and Mitchell, 2012).

Adhesion study presented that there were high accumulations of bacterium around BO cells (FLO-1, CP-D). This was similar to that reported by Man (2010) in which intestinal Caco 2 and HT29 cell lines invaded by this organism. He documented that campylobacter species in particular C. concisus could modulate barrier permeability by attachment. Attachment is the first mechanism of bacterial virulence factor to facilitate injection of invasion antigen and toxins (CDT and ZOT), increase attachment of specific sticky end of bacterium, induce expression of pro-inflammatory cytokines, activate entry into host cell, control cytoskeletal or junctional function, and change in tissue stem cell homeostasis (Man et al., 2010; Vogelmann et al., 2007).

CDXs gene was the first selected biomarker in this study. Our finding revealed that $C$. concisus induces high level of CDX1 in FLO-1. There are number of activated genes in $\mathrm{BO}$ compared with normal oesophageal that might play different role but among them CDXs genes (CDX1 and CDX2), CDX1 plays a central role in the development of metaplasia and induction of cellular differentiation in oesophageal epithelial cells, while CDX2 is regulated by various environmental factors (Makita et al., 2013). This process has been detected in BO (Tamagawa et al., 2013), in gastric cancer related to H. pylori and in intestinal metaplasia and dysplasia with frequent expression of CDX1 and CDX2 (Kang and Lee, 2011). In addition, microarray analysis of normal oesophagus, Barrett's tissues, and small intestinal biopsies have shown significant expression of CDX1 and c-myc. It has been reported that overexpression of CDXs genes in the glandular epithelium of the mice stomach lead to intestinal metaplasia. These show Cdx transcription factors can change glandular cell fates which reveal overexpression of $\mathrm{Cdx} 1$ duo to the effect of $C$. concisus might play a role in BO (Stairs et al., 2008).

The next step of our study was to observe the role of
COX2 gene. In vitro studies have shown overexpression of COX2 in angiogenesis, inhibition of immune surveillance, reduction of apoptosis, cell adhesion, decreasing E-Cadherin expression, increased cell proliferation, and increasing invasive or metastatic potential and their role in oesophageal cancer cell lines via the effect of bile acid by inhibition of COX2 expression resulted in apoptotic cell death, proliferation activity, and prostaglandin E2 synthesis (Hashimoto et al., 2012). Beside, data display gradual enhancement in the expression of COX2 throughout the sequence of $\mathrm{BO}$ to malignancy, reduction of CDX2 and increase in CDC2 (cell division cycle 2) (Villanacci et al., 2006). Evidence indicate expression of COX2, CDX2, and MUC2 on direct samples of BO which show high level of their expression in the intestinal metaplastic epithelium than in distant and non-goblet columnar epithelium (Gajjar et al., 2012). However, our finding showed that although $C$. concisus suppressed expression of COX 2 in $\mathrm{BO}$ cell lines, the COX2 expression had slight increase between metaplastic (CP-A) and dysplastic (CP-D) cells. Investigations have shown that any alternations in the p53, CDX1, and COX2 genes would results in various abnormalities and genetic damage. This variation in $\mathrm{BO}$ results in 16-fold higher risk of OA than those without any changes in these markers. Even, molecular epidemiology has revealed that the prevalence of positive p53 immunoreactivity in different stages of Barrett's progression linked to significant rates of $\mathrm{p} 53$ overexpression. This indicates that p53 in concert with other tumour progression markers is switched on in early stages of $\mathrm{BO}$ due to environmental factors and leads to abnormalities in the cell cycle (Turkmen et al., 2012). Chronic inflammation can influence unrestrained proliferation which leads to production of unwanted proteins as a result of CDXs genes or p53 gene (Hritz et al., 2009). Since apoptosis is usually programmed by $\mathrm{p} 53$ to discount death or abnormal cells in cell cycle by binding to TNF receptors and Fas, any disruption in this pattern will results in unwanted cells. Similarly, cell proliferation and p53 overexpression in OA patient samples compared to healthy group have been reported to account for the progression of BO to OA (Fichter et al., 2011). Thus, association between the effect of COX2 and p53 and CDXs in the progression of $\mathrm{BO}$ could initiate risk of OA (Akutko and Matusiewicz, 2017). Providing that C. concisus can induce the operation of signalling pathway links to the activation of $\mathrm{p} 53$, it will create genetic instability leading to the establishment of cellular abnormalities and activating expression of CDX1 and COX2 (Mozaffari Namin et al., 2015b).

Each of the studied molecular markers expresses at different stages of BO transformation but there are close relationship between their activation and the induction of multiple cellular pathways in OA. We therefore considered gene expression profiles of key signalling factors in infection with $C$. concisus and also in current studies (Akutko and Matusiewicz, 2017; Di Pilato et al., 2016) there have been considered its role as a new agent in gastrointestinal diseases. Findings stated that gastric cancer is caused by long-term co-existence of $H$. pylori 
with host cells. This extended process associates with a robust modulation of different signalling keys (such as p53 mutation, TNF $\alpha$ and IL18 modulation, and APC) and induction a multiple mechanisms from mucosal responses (Toll-like receptors) to the immune responses. These results point to might bacterial involvement/roles in $\mathrm{BO}$ transition to focus in more investigation.

In conclusion, despite unclear cellular and molecular mechanism of $\mathrm{BO}$ transition to $\mathrm{AE}$, we postulate that $\mathrm{BO}$ creates new microenvironment that facilitates $\mathrm{BO}$ biofilm formation specifically $C$. concisus which in turn induce an inflammatory microenvironment favourable for induction or exacerbation of BO progression to OA. However, it still need more investigation to been answered.

\section{Acknowledgments}

I would like to thank late Professor George Macfarlane, Dr Sandra Macfarlane for guidance and special thank Dr Bahram Bahrami for paper review. This work was semifunded by the International Campus (TUMS-IC), the Vice-Chancellor for Research grant (No. 24099) of Tehran University of Medical Sciences (Tehran, Iran).

\section{References}

Akutko K, Matusiewicz K (2017). Campylobacter concisus as the etiologic agent of gastrointestinal diseases. Adv Clin Exp Med, 26, 149-54.

Bahrami B, Macfarlane S, Child MW, Macfarlane GT (2011). Adherence and cytokine induction in Caco-2 cells by bacterial populations from a three-stage continuous-culture model of the large intestine. Appl Environ Microbiol, 77, 2934-42.

Blackett KL, Siddhi SS, Cleary S (2013). Oesophageal bacterial biofilm changes in gastro-esophageal reflux disease, Barrett's and oesophageal carcinoma: association or causality? Aliment Pharm Ther, 37, 1084-92.

Di Pilato V, Freschi G, Ringressi MN, Pallecchi L, Rossolini GM (2016). The esophageal microbiota in health and disease. Ann NY Acad Sci, ISSN 0077-8923. DOI: 10.1111.nyas.13127.

Enberg J, Bang D (2005). Campylobacter concisus: an evaluation of certain phenotypic and genotypic characteristics. Clin Microbiol Infect, 11, 288-95.

Fichter CD, Herz C, Münch C (2011). Occurrence of multipolar mitoses and association with Aurora-A/-B kinases and p53 mutations in aneuploid esophageal carcinoma cells. BMC Cell Biol, 12, 13-17.

Furrie E, Macfarlane S, Kennedy A (2007). Synbiotic therapy (Bifidobacterium longum/Synergy 1) initiates resolution of inflammation in patients with active ulcerative colitis: a randomised controlled pilot trial. Gut, 54, 242-9.

Gajjar M, Candeias MM, Malbert-Colas L (2012). The p53 mRNA-Mdm2 interaction controls Mdm2 nuclear trafficking and is required for $\mathrm{p} 53$ activation following DNA damage. Cancer Cell, 21, 25-35.

Gibson MK, Dhaliwal AS, Clemons NJ (2013). Barrett's esophagus: cancer and molecular biology. Ann NY Acad Sci, 1300, 296-314.

Hashimoto N (2012). Expression of COX2 and p53 in rat esophageal cancer induced by reflux of duodenal contents. ISRN Gastroenterol, ID 914824, 5.

Hritz I, Gyorffy H, Molnar B (2009). Increased p53 expression in the malignant transformation of Barrett esophagus is accompanied by an upward shift of the proliferative compartment. Pathol Oncol Res, 15, 183-92.

Ismail Y, Lee H, Riordan SM, Grimm MC, Zhang L (2013). The effects of oral and enteric Campylobacter concisus strains on expression of TLR4, MD-2, TLR2, TLR5 and COX-2 in HT-29 Cells. PLoS One, $\mathbf{8}$, e56888.

Jonge DPJF, Blankenstein MV, Grady WM, Kuipers EJ (2014). Barrett's esophagus: epidemiology, cancer risk and implications for management. Gut, 63, 191-202.

Kaakoush NO, Deshpande NP, Wilkins MR (2011). The pathogenic potential of Campylobacter concisus strains associated with chronic intestinal diseases. PLoS One, 6, e29045.

Kaakoush NO, Man SM, Lamb S (2010). The secretome of Campylobacter concisus. FEBS J, 277, 1606-17.

Kaakoush NO, Mitchell HM (2012). Campylobacater concisus- a new player in intestinal disease. Front Cell Infect Microbiol, 2, 1-15.

Kalischuk LD, Inglis GD (2011). Comparative genotypic and pathogenic examination of Campylobacter concisus isolates from diarrheic and non-diarrheic humans. BMC Microbiol, 11, 53-8.

Kang JM, Lee BH (2011). CDX1 and CDX2 expression in intestinal metaplasia, dysplasia and gastric cancer. Korean Acad Med Sci, pISSN; 1011-8934. DOI: 10.3346/ jkms.2011.26.5.647.

Leung WD, Waxman I (2014). Barrett's esophagus: treatment options and management. Springer, pp 201-14.

Lim YC, Fitzgerald RC (2013). Diagnosis and treatment of Barrett's esophagus. Ox J Med Bri Med Bul, 117-32. DOI: 10.1038/ajg.2015.322.

Maaser K, Daubler P, Barthel B, et al (2008). Oesophageal squamous cell neoplasia in head and neck cancer patients: upregulation of COX-2 during carcinogenesis. Br J Cacner, 88, 1217-22.

Macfarlane GT, Blackett KL, Nakayama T, Steed H, Macfarlane $\mathrm{S}$ (2009). The gut microbiota in inflammatory bowel disease. Curr Pharm Design, 15, 1528-36.

Macfarlane S, Furrie E, Cummings JH, Macfarlane GT (2004). Chemotaxonomic analysis of bacterial populations colonizing the rectal mucosa in patients with ulcerative colitis. Clin Infect Dis, 38, 1690-9.

Makita K, Kitazawa R, Semba S (2013). Cdx2 expression and its promoter methylation during metaplasia-dysplasia-carcinoma sequence in Barrett's esophagus. World J Gastroenterol, 19, 536-41.

Man SM, Kaakoush NO, Leach ST (2010). Host attachment, invasion, and stimulation of proinflammatory cytokines by Campylobacter concisus and other non-Campylobacter jejuni campylobacter species. J Infect Dis, 202, 1855-65.

Mizoshita T, Inada K, Tsukamoto T (2013). Expression of $\mathrm{Cdx} 1$ and $\mathrm{Cdx} 2 \mathrm{mRNAs}$ and relevance of this expression to differentiation in human gastrointestinal mucosa with special emphasis on participation in intestinal metaplasia of the human stomach. Gastric Cancer, 4, 185-191.

Mozaffari Namin B, Daryani NE, Mirshafiey A, Sharifi Yazdi MK, Soltan Dallal MM (2015a). The effect of probiotics on the expression of Barrett's esophagus biomarkers. $J$ Med Microbiol, 64, 348-54.

Mozaffari Namin B, Soltan Dallal MM, Daryani N (2015b). The effect of Campylobacter concisus on the expression of IL18, TNF $\alpha$, and p53 on Barrett's esophagus. JJM, 8, e26393.

Rosenvinge ECV, O'May GA, Macfarlane S, Macfarlane GT, Shirtliff ME (2013). Microbial biofilms and gastrointestinal diseases. Pathol Dis, 67, 25-38.

Stairs DB, Nakagawa H, Klein-Szanto A (2008). Cdx1 and c-Myc foster the initiation of transdifferentiation of the normal esophageal squamous epithelium toward Barrett's 
esophagus. PLoS One, 10, e3534.

Tamagawa Y, Ishimura N, Uno G (2012). Notch signaling pathway and $\mathrm{Cdx} 2$ expression in the development of Barrett's esophagus. Lab Invest, 92, 896-909.

Turkmen IC, Bassullu N, Uraz S (2012). CDX2, COX2 and MUC2 expressions in Barrett's esophagus: can they be useful in determination of the dysplasia?. Turk Patol Derg, 28, 251-8.

Villanacci V, Rossi E, Zambelli A (2006). Cox-2, Cdx-2, and Cdc-2 immunohistochemical assessment for dysplasia-carcinoma progression in Barrett's esophagus. Dig Liv Dis, 33, 305-11.

Vogelmann R, Amieva MR (2007). The role of bacterial pathogens in cancer. Curr Opin Microbiol, 10, 76-81.

Yang L, Francois F, Pei Z (2012). Molecular pathways: pathogenesis and clinical implications of microbiome alteration in esophagitis and Barrett's esophagus. Clin Cancer Res, 18, 2133-44.

\section{(c) (i) (8)}

This work is licensed under a Creative Commons AttributionNon Commercial 4.0 International License. 